\title{
Gilles Bonnet, L'Ecriture comique de J.-K. Huysmans
}

\section{Cecilia Torelli}

\section{(2) OpenEdition}

\section{Journals}

\section{Edizione digitale}

URL: https://journals.openedition.org/studifrancesi/41056

DOI: 10.4000/studifrancesi.41056

ISSN: 2421-5856

\section{Editore}

Rosenberg \& Sellier

\section{Edizione cartacea}

Data di pubblicazione: 1 juillet 2004

Paginazione: 216

ISSN: 0039-2944

\section{Notizia bibliografica digitale}

Cecilia Torelli, «Gilles Bonnet, L'Ecriture comique de J.-K. Huysmans», Studi Francesi [Online], 142 (XLVIII I I) | 2004, online dal 30 novembre 2015, consultato il 09 septembre 2021. URL: http://

journals.openedition.org/studifrancesi/41056 ; DOI: https://doi.org/10.4000/studifrancesi.41056

\section{Questo documento è stato generato automaticamente il 9 septembre 2021.}

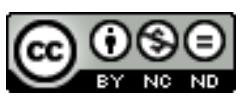

Studi Francesi è distribuita con Licenza Creative Commons Attribuzione - Non commerciale - Non opere derivate 4.0 Internazionale. 


\title{
Gilles Bonnet, L'Ecriture comique de J.-K. Huysmans
}

\author{
Cecilia Torelli
}

\section{NOTIZIA}

GILLES BONNET, L'Ecriture comique de J.-K. Huysmans, Paris, Honoré Champion, 2003, p. 332

1 L'A. si propone di illustrare, attraverso una progressiva espansione dell'analisi condotta, la scrittura comica in Huysmans, al fine di conferirle quel giusto merito che la critica non sempre ha riconosciuto. Tenendo presenti le parole di Zola, Il y a dans votre outrance un comique spécial que personne n'a et qui est une de vos originalités supérieures, secondo l'A. il comico appare in grado di influenzare l'opera nella sua totalità, che, senza di esso, perderebbe parte della sua ricchezza semantica. Questo specifico tipo di scrittura trova la sua originalità nel percorso che traccia per il lettore, con il quale instaura una relazione di tipo ludico immersa in una pluralità di significati e di interrogativi continuamente sollevati e al quale richiede una mobilità intellettuale non irrilevante. Lo studio tocca problematiche inerenti l'area del realismo (piuttosto che del decadentismo) e la spinosa questione della conversione. Particolare attenzione viene riservata all'analisi delle due pratiche della satira e della caricatura: esse si muovono tra una violenza che sfocia in ambito sociale e una sorta di compiacimento dello scrittore per la propria virtuosità artistica, operano nel campo del reale e riescono a compiere la loro opera di distruzione attraverso il ridicolo. Non meno importante è la pantomima, attraverso cui viene espressa una comicità che, talvolta, può disorientare il lettore. Ma l'azione del comico è ancora più estesa e profonda: citando le parole dell'A., è cet acide capable de séparer deux substances, roman et romanesque. Questa separazione risulta ben evidente in A rebours, ove gli episodi improntati al ridicolo vogliono mettere in discussione le leggi basilari del romanzo e ove il rifiuto diventa derisione. 
2 Concludono il volume un indice dei nomi e una bibliografia selettiva che tocca diversi temi: Huysmans, le problematiche contemporanee, il comico, articolato in humour, ironia, caricatura, satira, pantomima, pastiche e parodia. 